\title{
Antilisterial Activity of Lactose Fatty Acid Esters in Milk
}

\author{
Seung-Min Lee1, Brian Nummer1, Ashwini Wagh², Marie K. Walsh ${ }^{*}$ \\ ${ }^{1}$ Department of Nutrition, Dietetics, and Food Sciences, Utah State University, Logan, Utah, USA \\ ${ }^{2}$ The Clorox Service Company, Pleasanton, California, USA \\ Email: *marie.walsh@usu.edu
}

How to cite this paper: Lee, S.-M., Nummer, B., Wagh, A. and Walsh, M.K. (2019) Antilisterial Activity of Lactose Fatty Acid Esters in Milk. Food and Nutrition Sciences, 10, 750-760. https://doi.org/10.4236/fns.2019.107055

Received: May 22, 2019

Accepted: July 16, 2019

Published: July 19, 2019

Copyright (c) 2019 by author(s) and Scientific Research Publishing Inc. This work is licensed under the Creative Commons Attribution International License (CC BY 4.0).

http://creativecommons.org/licenses/by/4.0/

(c) (i) Open Access

\begin{abstract}
Carbohydrate fatty acid esters have been shown to inhibit the growth of bacteria in growth media. In this study, the antilisterial activities of the carbohydrate esters lactose monodecanoate (LMD) and lactose monolaurate (LML) were tested in milk samples with variable fat content (up to $10 \%$ ) and at different temperatures $\left(37^{\circ} \mathrm{C}, 24^{\circ} \mathrm{C}\right.$ and $5^{\circ} \mathrm{C}$ ) after inoculation with a 5-strain Listeria monocytogenes cocktail. Both LMD and LML demonstrated antilisterial properties against L. monocytogenes in milk, with the observed log reductions in the LMD milk samples being higher than those in the LML samples at all tested temperatures. LMD in $1 \%$ and $2 \%$ fat milk was found to be bactericidal with no Listeria growth by day 6. LMD showed significant antilisterial activity in milk samples containing up to $9 \%$ fat at $37^{\circ}$ and in samples with up to $3.5 \%$ fat at $24^{\circ} \mathrm{C}$ and in milk samples with up to $2 \%$ fat at $5^{\circ} \mathrm{C}$. LML showed significant Listeria $\log$ reductions at $37^{\circ} \mathrm{C}$ with milk containing up to $9 \%$ fat but showed no microbial inhibition in milk in any samples at $24^{\circ} \mathrm{C}$ and $5^{\circ} \mathrm{C}$. Although carbohydrate fatty acid esters have proven microbial bactericid$\mathrm{al} /$ bacteriostatic properties in growth media, their antimicrobial properties are reduced in a food system containing fat and at temperatures lower than $37^{\circ} \mathrm{C}$. The significance of this research is identifying food constituents and storage temperatures that limit the microbial inhibitory properties of lactose esters to ensure appropriate use as potential food grade antilisterial agents.
\end{abstract}

\section{Keywords}

Lactose Monodecanoate, Lactose Monolaurate, Antilisterial Activity, Milk, Fat, Temperature

\section{Introduction}

Carbohydrate esters are nonionic surfactants used in a variety of applications in the 
food, pharmaceutical, detergent and personal care industries [1] [2]. They consist of a hydrophilic carbohydrate moiety (mono- or di-saccharide) esterified to a fatty acid lipophilic tail (fatty acids from 8 to 18 carbons have been used) and sucrose esters are available commercially (Sisterna, The Netherlands and Mitsubishi-Kagaku Foods Corporation, Tokyo, Japan). These esters contain both microbial inhibitory [1] [2] [3] and emulsification properties [4] [5] [6]. They are biodegradable, harmless to the environment, non-toxic and non-skin irritant surfactants [2] [7].

Previous research [4] [8] [9] [10] [11] has documented the bactericidal/inhibitory activity of carbohydrate esters in growth media. Our lab was the first to enzymatically synthesize lactose esters [12] and shows the microbial inhibitory properties of lactose monolaurate (LML) [9]. LML was bactericidal to $L$. monocytogenes strains in growth medium at $37^{\circ} \mathrm{C}$ at concentrations between 3 and $5 \mathrm{mg} / \mathrm{ml}$ (5.7 to $9.5 \mathrm{mM}$ ). Further research investigated the influence of the fatty acid chain length on the antimicrobial/bacteriostatic properties of lactose esters [3]. This research showed that LML was the most effective ester exhibiting microbial inhibitory concentration (MIC) and minimum bactericidal concentrations (MBC) values of $<5 \mathrm{mg} / \mathrm{ml}$ for the Gram positive bacteria Bacillus cereus, Mycobacterium KMS, Streptococcus suis, and L. monocytogenes in growth media at $37^{\circ} \mathrm{C}$ but no activity against the Gram-negative bacteria tested. Lactose monodecanoate (LMD) also exhibited microbial inhibition with MIC and MBC values of $<5 \mathrm{mg} / \mathrm{ml}$ for B. cereus, $M$. KMS, S. suis, and Enterococcus faecalis. The esters lactose monooctanoate (LMO) and lactose monomyristate (LMM) were also inhibitory but not to the extent as LML and LMO. This research suggested that the fatty acid ester chain length significantly affects the microbial inhibitory properties of lactose esters when conducted in bacterial growth medium at $37^{\circ} \mathrm{C}$.

An additional study [13] investigated the microbial inhibitory properties of LML in dairy products inoculated with a 5-strain cocktail of $L$. monocytogenes at $37^{\circ} \mathrm{C}$. LML exhibited a bactericidal effect in low-fat dairy products ( $1 \%$ fat) including milk and yogurt and a bacteriostatic effect in the products listed with a higher fat content at $37^{\circ} \mathrm{C}$. There was no inhibition in any of the dairy products at $5^{\circ} \mathrm{C}$. Therefore, both temperature and fat content influence the microbial inhibitory activities of LML.

There have been few studies on the microbial inhibitory activity of carbohydrate esters in food systems [13] [14] [15]. It is assumed that the microbial activities of carbohydrate esters in foods will not be the same as in media due to the potential interactions with food constituents including proteins, carbodydrates and lipids. This study investigated the effects of fat content and temperature on the antilisterial activities of both LML and LMD in milk at various fat contents and at temperatures of $5^{\circ} \mathrm{C}, 24^{\circ} \mathrm{C}$ and $37^{\circ} \mathrm{C}$ to evaluate the use of lactose esters as potential antilisterial agents in food systems.

\section{Materials and Methods}

\subsection{Bacterial Strains}

The bacterial strains used are listed in Table 1. Different clinical isolates of Listeria 
Table 1. Series of microorganisms involved in the study.

\begin{tabular}{ccccc}
\hline No. & Microorganisms & ATCC number./serovar & Gram reaction $^{\mathrm{a}}$ & Growth medium $^{2}$ \\
\hline 1 & Listeria monocytogenes & FSL C1-056 & + & BHI \\
2 & Listeria monocytogenes & FSL J1-177 & + & BHI \\
3 & Listeria monocytogenes & FSL N3-013 & + & BHI \\
4 & Listeria monocytogenes & FSL R2-499 & + & BHI \\
5 & Listeria monocytogenes & FSL N1-227 & + & BHI \\
\hline
\end{tabular}

${ }^{\mathrm{a}}+$, Gram-positive bacteria.

(C1-056, J1-177, N1-277, N3-013 and R2-499) were obtained from Dr. Martin Wiedmann, director of the International Life Sciences Institute North American Database at Cornell University.

\subsection{Materials and Equipment}

A high-performance liquid chromatography (HPLC) (Beckman System Gold 125 Solvent Module, Ontario, Canada) equipped with Luna 5 lm C18 $100 \AA$ (250 $\mathrm{mm} \times 4.6 \mathrm{~mm}$, Phenomenex, Torrance, CA, USA), an evaporative light scattering detector (Agilent Technologies, Santa Clara, CA, USA), incubator shaker (Beckman, USA), spectrophotometer (Beckman, Portland, OR, USA) and Ultra-turrax T25 (Janke and Kunkel, Staufen, Germany) were provided by Utah State University. Lactose (Proliant, IA, USA), acetonitrile and $15 \mathrm{ml}$ pre-sterilized centrifuge tubes (Thermo Fisher, PA, USA) were used. Brain heart infusion (BHI) media, lipase TM3 (immobilized from Thermomyces lanuginosus), Whatman glass microfiber filters, molecular sieves (3A), 2-methyl-2-butanol (2M2B) (dried using 10\% 3A molecular sieves), dimethyl sulfoxide (DMSO) and $1.5 \mathrm{ml}$ cuvettes were supplied by Sigma (Aldrich, MO, USA). Vinyl decanoate and vinyl laurate were from TCI (Portland, OR, USA). Sterile, shelf-stable low-fat milk ( $1 \%$ fat), reduced fat milk ( $2 \%$ fat), whole milk ( $3.5 \%$ fat) and whipping cream ( $36 \%$ fat) were obtained from Gossner Foods Inc. (Logan, UT, USA).

\subsection{Synthesis of Lactose Esters}

Enzymatic synthesis of LML was performed as previously described [12]. Synthesis of LMD was conducted using lactose, vinyl decanoate, molecular sieves and immobilized lipase TM3. For a $60 \mathrm{ml}$ reaction in 2M2B, $3 \mathrm{~g}$ of lactose, $6 \mathrm{~g}$ of dried molecular sieves, $870 \mu \mathrm{l}$ of vinyl decanoate (lactose to fatty acid ratio of 1:1) and $1.8 \mathrm{~g}$ TM3 were combined. The reactions were assembled in a $100 \mathrm{ml}$ glass bottle and incubated at $55^{\circ} \mathrm{C}$ and $90 \mathrm{rpm}$ for 2 days. The amount of LMD synthesized was determined using HPLC with the evaporative light scattering detector set at $60^{\circ} \mathrm{C}$ with a nitrogen gas pressure of 3.55 bar. There was a mobile phase gradient from $10 \%$ acetonitrile-water $(40: 60, \mathrm{v} / \mathrm{v})$ to $95 \%$ acetonitrile-water $(95: 5, \mathrm{v} / \mathrm{v})$.

\subsection{Purification of Lactose Esters}

For ester purification, the $2 \mathrm{M} 2 \mathrm{~B}$ reactions were filtered through a Whatman 
glass microfiber filter then dried in a hood for $48 \mathrm{~h}$. The dry LML was suspended in a 50\% hexane, $50 \%$ water solution while the dry LMD was suspended in a 50\% ethanol, 50\% water solution. These were then placed in a separatory funnel. The lower aqueous layer containing the esters was drained into a beaker and dried in a hood for $48 \mathrm{~h}$. After completely drying, the product powder was suspended in hexane, and then centrifuged for $15 \mathrm{~min}$ at room temperature at $2000 \times \mathrm{g}$ and the supernatant analyzed via HPLC for the presence of di- tri- or higher fatty acid saccharides. If di- or higher fatty acids esters were present in the hexane, the hexane fraction was discarded. The hexane extraction was repeated until only the monoester was present in the pellet. The purities of the lactose esters were confirmed to be greater than $85 \%$ by HPLC analysis.

\subsection{Microbial Inhibitory Studies in Milk}

A 5-strain cocktail of L. monocytogenes included strains C1-056, J1-177, N1-277, N3-013, and R2-499 was prepared. The 5 stocks were stored individually at $-80^{\circ} \mathrm{C}$, and each individual freezer stock $(20 \mu \mathrm{l})$ was added to $15 \mathrm{ml}$ of BHI media. The Listeria strains were grown at $37^{\circ} \mathrm{C}$ and $200 \mathrm{rpm}$ for $24 \mathrm{~h}$. Aliquots (2 $\mathrm{ml}$ ) from each strain were combined in a test tube to develop the 5-strain stock cocktail. Aliquots $(315 \mu \mathrm{l})$ of the stock cocktail were grown in BHI media (12 $\mathrm{ml}$ ), and incubated with shaking at $37^{\circ} \mathrm{C}$ for $4 \mathrm{~h}$. Aliquots of the 5 -strain stock cocktail were kept at $-80^{\circ} \mathrm{C}$. The growing cultures were monitored by optical density measurements at $600 \mathrm{~nm}$ (OD600) and diluted with fresh media to reach an OD600 of 0.2, which was determined by plating on BHI agar to be equivalent to between $10^{5}$ and $10^{6} \mathrm{CFU} / \mathrm{ml}$. After the optical density was standardized at 0.2 , an aliquot of the culture, $100 \mu \mathrm{l}$ was mixed with $10 \mathrm{ml}$ of fresh media, and then centrifuged $\left(4000 \mathrm{rpm}, 15 \mathrm{~min}, 4^{\circ} \mathrm{C}\right)$. The resulting pellets from the centrifugation were then resuspended in $10 \mathrm{ml}$ of fresh $0.1 \%$ phosphate-buffered saline (PBS). This allowed the treatment cultures to be standardized for each test.

Identical stock solution concentrations $(93.75 \mathrm{mg} / \mathrm{ml}$ ) each of LMD and LML were prepared in 100\% DMSO. Ester stock solutions were diluted into sterilized milk to give a final ester concentration of $5 \mathrm{mg} / \mathrm{ml}$ containing $2.5 \%$ DMSO as previously described [3]. Sterile milk samples with various levels of fat levels we purchased ( $1 \%, 2 \%, 3.5 \%$, and $36 \%$ fat). Milk samples with higher fat levels were also prepared by mixing $1 \%$ fat milk with heavy whipping cream (36\% fat). Each of the various fat levels was achieved by calculating how much total fat was needed in each for a given volume of $100 \mathrm{ml}$. Once each samples' fat content was calculated, the required amount of cream to achieve that level was added with the remaining volume being filled by $1 \%$ fat milk and then blended at 18,000 rpm (Ultra-turrax T25) for 1 min to obtain a homogeneous solution. LMD was tested at fat contents from 0 (BHI media) to $10 \%$ at $37^{\circ} \mathrm{C}, 0 \%-7 \%$ fat at both 24 and $5^{\circ} \mathrm{C}$. LML was tested at $0 \%-9 \%$ fat at $37^{\circ} \mathrm{C}, 0 \%-2 \%$ fat at both $24^{\circ} \mathrm{C}$ and $5^{\circ} \mathrm{C}$. The lactose esters in a stock solution were then added to the milk samples in $15 \mathrm{ml}$ sterile tubes for a final concentration $5 \mathrm{mg} / \mathrm{ml}$ and each tube contained 
a total of $10 \mathrm{ml}$, containing $10^{5}$ and $10^{6} \mathrm{CFU} / \mathrm{ml}$ of the Listeria cocktail prepared as described above. Controls contained the same concentration of DMSO as the treatments. These were then incubated at $5^{\circ} \mathrm{C}, 24^{\circ} \mathrm{C}$ and $37^{\circ} \mathrm{C}$, respectively. Each combination of milk fat level, lactose ester treatment, and microbial inoculation was tested a total of eight times and was compared to the control. Survival and growth of L. monocytogenes were monitored daily for 6 days to determine the log reduction by plate counts. A paired T-test was used to compare the treatments with the controls at each concentration to determine if the treatments were significantly different from the controls.

\section{Results}

LMD was evaluated for antilisterial effect at different milk fat contents ( $1 \%$ to $10 \%)$ at $37^{\circ} \mathrm{C}$ with a final concentration of $5 \mathrm{mg} / \mathrm{ml}$ ester in each sample. BHI growth media was also tested along with the milk samples for comparison. The results in Table 2 show the log reductions at each fat content and at $37^{\circ} \mathrm{C}, 24^{\circ} \mathrm{C}$ and $5^{\circ} \mathrm{C}$. Figure 1 shows the log reduction in BHI media and milk at various fat contents over the time course of the study (6 days). The results in Table 2 summarize the log reductions from each time course study. When testing the antimicrobial activity of LMD in growth media at $37^{\circ} \mathrm{C}, 3$ and $8.4 \mathrm{log}$ reductions in cells were observed after 1 and 3 days respectively with no viable cells on day 3 . With $1 \%$ fat milk, 4.5 and 8.2 log reductions were observed on days 1 and 3 with no bacterial growth at day 3 . With $2 \%$ fat milk, 2 and $6.5 \log$ reductions were observed on days 1 and 3 with no bacterial growth on day 6 . With $3.5 \%$ fat milk, 2 and $6 \log$ reductions were observed on days 1 and 3. With 7\% milk fat, 1.8, 4.8, and $6 \log$ reductions were observed at days 1, 3 and 6 . With $9 \%$ milk fat, $0.8,1.7$

Table 2. Log reductions ${ }^{1}$ of a 5 -strain Listeria cocktail with various fat contents with $5 \mathrm{mg} / \mathrm{ml}$ lactose decanoate (LMD).

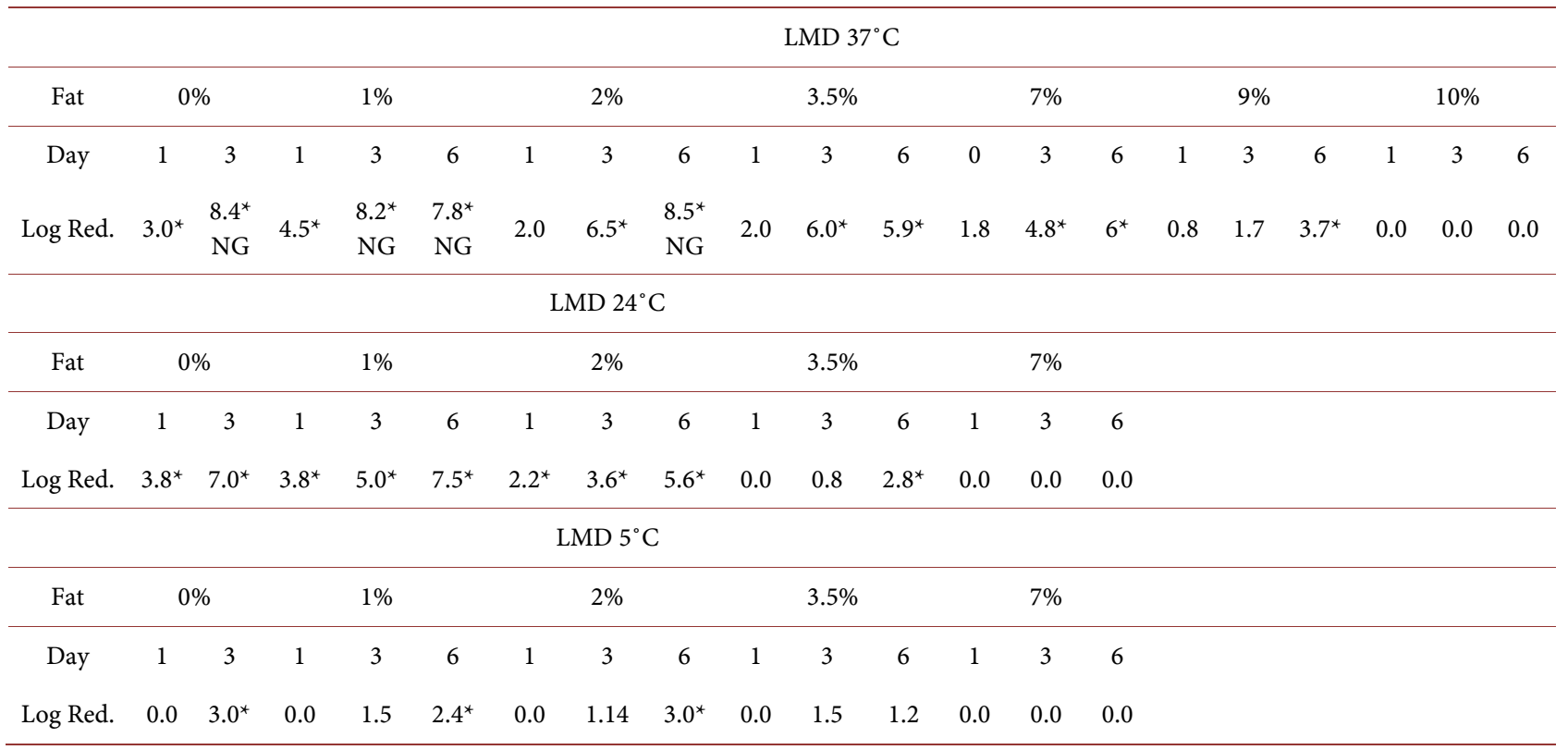

${ }^{1} \log$ Reductions compared to control (Log Red.); ${ }^{\star D e n o t e s ~ a ~ s i g n i f i c a n t ~ l o g ~ r e d u c t i o n ~ f r o m ~ t h e ~ c o n t r o l ; ~ N G ~=~ N o ~ G r o w t h . ~}$ 


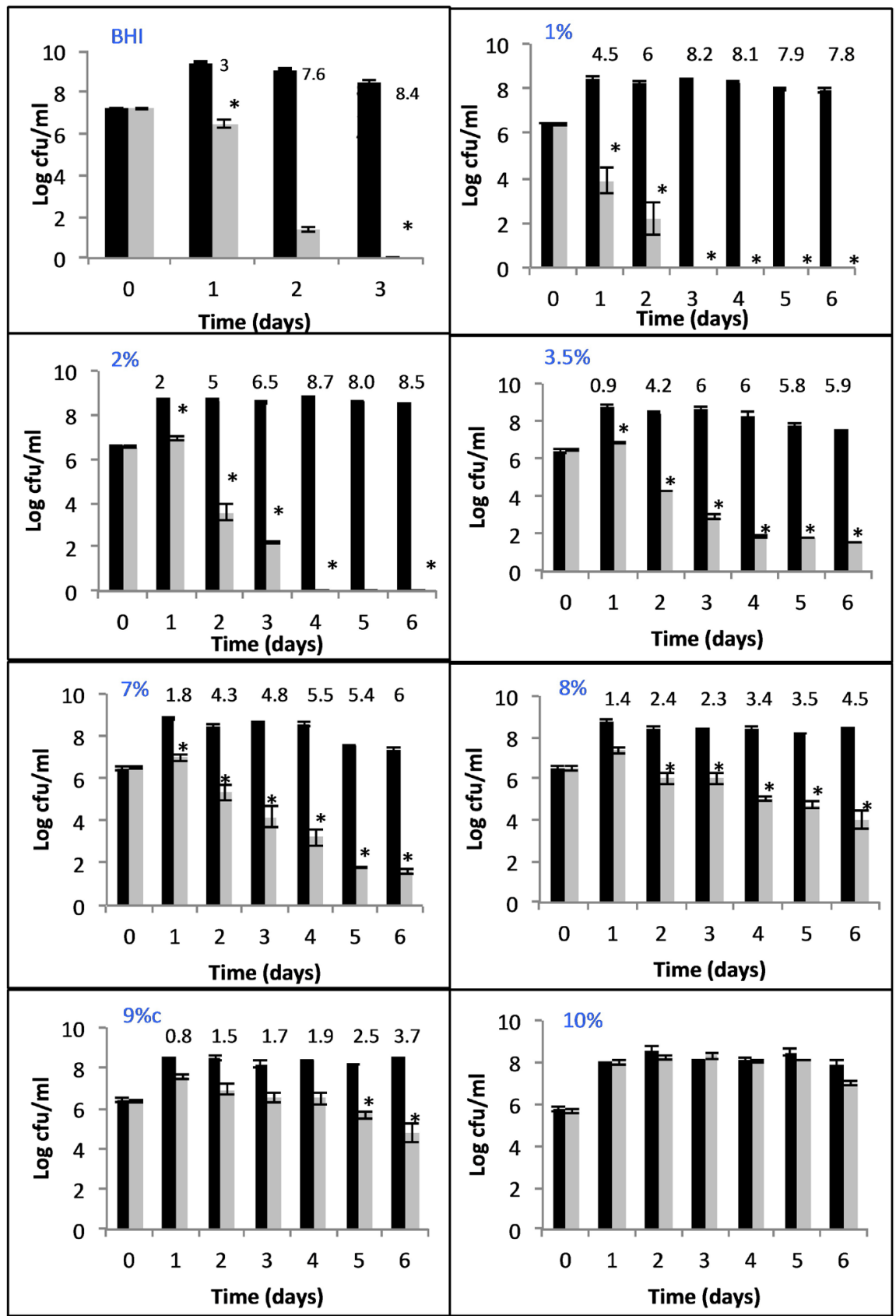

Figure 1. Average $\log \mathrm{CFU} / \mathrm{ml}$ results of a 5-strain cocktail of L. monocytogenes treated with $5 \mathrm{mg} / \mathrm{ml} \mathrm{LMD} \mathrm{in} \mathrm{milk} \mathrm{at} \mathrm{various} \mathrm{fat} \mathrm{contents} \mathrm{over} \mathrm{time} \mathrm{at} 37^{\circ} \mathrm{C}$. The black bars are the controls and the light grey bars are the treatments. The error bars represent the standard deviations and the asterisks indicate a significant difference from the control. The fat content in the milk is given in blue font and the log reductions in treatments are given over the bars.

and $3.7 \log$ reductions were observed at days 1,3 , and 6 respectively. LMD in milk up to $7 \%$ fat $(3.5 \%$ fat is whole milk) was found to be an effective antilisterial agent resulting in 6 log reductions after 6 days. Additionally, milk samples with fat concentrations up to $9 \%$ showed measurable and significant log reductions of $L$. monocytogenes at 6 days. There was no observed inhibition of 
the L. monocytogenes with fat contents greater than $9 \%$ fat with LMD at $37^{\circ} \mathrm{C}$.

The antilisterial effectiveness of LMD was also tested at $24^{\circ} \mathrm{C}$ at different fat contents and the results are summarized in Table 2. Results of LMD at this temperature were as follows: in $1 \%$ fat milk, 5 and 7.5 log reductions in cells were observed after 3 and 6 days respectively; in $2 \%$ fat milk, 3.6 and 5.6 log reductions were observed on days 3 and 6; in 3.5\% fat milk, 0.8 and 2.8 log reductions were observed on days 3 and 6 . No additional log reductions were observed at fat contents greater than $3.5 \%$. The log reductions in BHI growth media were 3.8 and 7 on days 1 and 3 .

Additionally, the antilisterial effectiveness of LMD was tested at $5^{\circ} \mathrm{C}$ at different fat contents and summarized in Table 2. Results of LMD at this temperature were as follows: in $1 \%$ fat milk, 1.5 and 2.4 log reductions in cells were observed after 3 and 6 days respectively; in 2\% fat milk fat, 1.4 and $3 \log$ reductions were observed on days 3 and 6 . Log reductions were observed in $3.5 \%$ fat milk, but the reductions were not significant and no further log reductions were observed in milk at $7 \%$ fat. The log reductions in BHI growth media were 0 and 3 on days 1 and 3.

LML also was evaluated for antilisterial effect in media and in different milk fat samples $(1 \%$ to $10 \%)$ at $37^{\circ} \mathrm{C}$ with a final concentration of $5 \mathrm{mg} / \mathrm{ml}$ ester in each sample as summarized in Table 3. BHI growth media was also tested along with the milk samples for comparison. When testing the antimicrobial activity of LML in growth media at $37^{\circ} \mathrm{C}, 3$ and $8 \log$ reductions in cells were observed after 1 and 3 days respectively with no viable cells on day 3 . With $1 \%$ fat milk, 2, 3.7, and $7.4 \log$ reductions were observed on days 1,3 and 6 . With $2 \%$ fat milk 5 log reductions were observed on day 6 . With $3.5 \%$ milk fat, 3 log reductions were observed at day 6. Milk samples with fat concentrations up to $3.5 \%$ showed

Table 3. Log reductions ${ }^{1}$ of a 5 -strain Listeria cocktail with various fat contents with $5 \mathrm{mg} / \mathrm{ml}$ lactose monolaurate (LML).

\begin{tabular}{|c|c|c|c|c|c|c|c|c|c|c|c|c|c|c|c|c|c|}
\hline \multirow{3}{*}{$\begin{array}{l}\text { Fat } \\
\text { Day }\end{array}$} & \multicolumn{17}{|c|}{$\mathrm{LML} 37^{\circ} \mathrm{C}$} \\
\hline & \multicolumn{2}{|c|}{$0 \%$} & \multicolumn{3}{|c|}{$1 \%$} & \multicolumn{3}{|c|}{$2 \%$} & \multicolumn{3}{|c|}{$3.5 \%$} & \multicolumn{3}{|c|}{$7 \%$} & \multicolumn{3}{|c|}{$9 \%$} \\
\hline & 1 & 3 & 1 & 3 & 6 & 1 & 3 & 6 & 1 & 3 & 6 & 1 & 3 & 6 & 1 & 2 & 6 \\
\hline Log Red. & $3^{*}$ & $\begin{array}{c}8^{*} \\
\mathrm{NG}\end{array}$ & $2^{*}$ & $3.7^{*}$ & $7.4^{*}$ & 1.5 & $2.2^{*}$ & $5.0^{*}$ & 0.0 & 1 & $3.0^{*}$ & 0.0 & 1 & 1.8 & 0.0 & 0.0 & 0.0 \\
\hline \multicolumn{18}{|c|}{$\mathrm{LML} 24^{\circ} \mathrm{C}$} \\
\hline Fat & \multicolumn{2}{|c|}{$0 \%$} & \multicolumn{3}{|c|}{$1 \%$} & \multicolumn{3}{|c|}{$2 \%$} & & & & & & & & & \\
\hline Day & 1 & 3 & 1 & 1 & 3 & 1 & 3 & 6 & & & & & & & & & \\
\hline Log Red. & 0.0 & 0.0 & 0.0 & 0.0 & 0.0 & 0.0 & 0.0 & 0.0 & & & & & & & & & \\
\hline \multicolumn{18}{|c|}{$\operatorname{LML~} 5^{\circ} \mathrm{C}$} \\
\hline Fat & \multicolumn{2}{|c|}{$0 \%$} & \multicolumn{3}{|c|}{$1 \%$} & & $2 \%$ & & & & & & & & & & \\
\hline Day & 1 & 3 & 1 & 3 & 6 & 1 & 3 & 6 & & & & & & & & & \\
\hline Log Red. & 0.0 & 0.0 & 0.0 & 0.0 & 0.0 & 0.0 & 0.0 & 0.0 & & & & & & & & & \\
\hline
\end{tabular}

${ }^{1} \log$ Reductions compared to control (Log Red.); ${ }^{\star}$ Denotes a significant log reduction from the control; NG $=$ No Growth. 
measurable and significant log reductions of L. monocytogenes over 6 days, however, LML was not shown to be bactericidal in any of the milk samples. There was no observed inhibition of the L. monocytogenes in milk with greater than $7 \%$ milk fat at $37^{\circ} \mathrm{C}$.

The antilisterial effectiveness of LML was also tested at $5^{\circ} \mathrm{C}$ and $24^{\circ} \mathrm{C}$, respectively, at different fat contents (Table 3). Results of LML at $5^{\circ} \mathrm{C}$ and $24^{\circ} \mathrm{C}$ showed that there was no observed inhibition of the L. monocytogenes in BHI media or $1 \%$ and $2 \%$ milk fat samples at these temperatures.

\section{Discussion}

Previous research investigated the antilisterial activity of carbohydrate esters. Lee [3] showed that the fatty acid chain length of lactose esters significantly influenced the microbial inhibitory activity of these esters towards Listeria in growth media at $37^{\circ} \mathrm{C}$. The research showed MICs for LMD and LML for $L$. monocytogenes were less than $3 \mathrm{mg} / \mathrm{ml}(\leq 5.7 \mathrm{mM})$. A similar study [8] reported that the lauric ether of methyl $\alpha$ - $D$-glucopyranoside and the lauric ester of methyl $\alpha$ - $D$-mannopyranoside showed the greatest activity against $L$. monocytogenes at concentrations of $0.04 \mathrm{mM}$ which were also conducted at $37^{\circ} \mathrm{C}$ in growth media.

A previous study [13] showed that LML was bactericidal towards L. monocytogenes in milk and yogurt with $<1 \%$ fat and bacteriostatic in milk and yogurt at higher fat contents. Additionally, no growth inhibition was observed in the study at $5^{\circ} \mathrm{C}$ which is in agreement with this research. This current study focused on determining the antilisterial activities of both LMD and LML as influenced by fat content and temperature. Also, there are few reports in the literature on the log reductions of $L$. monocytogenes resulting from carbohydrate esters at temperatures below $37^{\circ} \mathrm{C}$.

Sucrose esters are approved for use in the European Union (ingredient E473) and in the United States. In the U.S., sucrose fatty acid esters are approved for use as emulsifiers and should be used in accordance with current good manufacturing practice and in an amount not to exceed that reasonably required to accomplish the intended effect [16]. We used a $5 \mathrm{mg} / \mathrm{ml}$ (equal to $0.5 \%$ ) level of ester in this research since most food emulsifiers are used at levels less than or equal to $1 \%$, thus research using higher ester concentrations would be interesting future research.

Both LMD and LML demonstrated antilisterial properties in tested milk samples, though the observed log reductions in the LMD treated milk samples were greater than those with $\mathrm{LML}$ at all tested temperatures $\left(5,24^{\circ} \mathrm{C}\right.$ and $\left.37^{\circ} \mathrm{C}\right)$. Both LML and LMD were bactericidal at $37^{\circ} \mathrm{C}$ in BHI media. For both esters, there was a decrease in Listeria log reductions with an increase in fat content. Previous research [13] suggested that the laurate (12 carbon fatty acid) moiety of LML was responsible for the bactericidal activity of LML. Since these esters include a fatty acid moiety, they may bound in the fat phase or at the fat-water surface leading to less ester available for antilisterial activity in samples containing fat. 
LMD (containing a 10 carbon fatty acid) showed significantly higher antimicrobial activity compared to LML at high-fat concentrations, suggesting that LMD may not partition into the fat phase as readily as LML and thus remain more available in the liquid phase for microbial inhibitory activity. Specifically, LMD may not partition into the fat phase until the fat content is greater than $7 \%$ while LML may partition into the fat phase at fat concentrations greater than $2 \%$.

One previous study investigated the antimicrobial activity of sucrose esters of laurate, palmitate and myristate [15] in salad dressing containing $35.2 \%$ oil. They showed that $1 \%(10 \mathrm{mg} / \mathrm{ml})$ sucrose monoesters were effective at inhibiting the growth of $Z$ ygosaccharomyces bailii in the salad dressing at $27^{\circ} \mathrm{C}$ and viable $Z$. bailii cells decreased to near undetectable levels after 9 days of storage. No temperatures other than $27^{\circ} \mathrm{C}$ were investigated for microbial inhibitory activity and they used twice the concentration of ester as used in this study but they did show that sucrose esters were inhibitory at a high-fat content.

Regardless of the fat content, the antilisterial activity of the lactose esters decreased with a decrease in temperature. There are several explanations for decreasing temperatures reducing antilisterial activity. First, lactose is one of the least soluble sugars and the alpha-monomer can precipitate from a $5 \%$ solution at refrigeration temperatures [17]. LML, with the longer fatty acid chain length, is predicted to be less water soluble than LMD, so fatty acid chain length along with lactose solubility may be the reason why LML was ineffective at microbial inhibition at $24^{\circ} \mathrm{C}$ and $5^{\circ} \mathrm{C}$. Also, hydrophobic interactions are directly dependent on temperature with lower temperatures decreasing or eliminating hydrophobic interactions. If the lactose esters' antilisterial activity were dependent upon hydrophobic interactions, the reduction or loss of these interactions would decrease or eliminate the antilisterial properties. Moreover, physical changes occur at reduced temperatures; it is possible that the listerial cell wall and membranes become less malleable or interactive at lower temperatures thus less permeable to a carbohydrate ester. Recently Shao [11] investigated the antimicrobial activity of sucrose monolaurate against $L$. monocytogenes. They showed that the sucrose ester caused pronounced damage to the cell membrane integrity and may form a hole in the peptidoglycan layer. Therefore, at low temperatures, the activity of carbohydrate esters is limited perhaps due to ester solubility, a decrease in necessary hydrophobic interactions or a more impermeable bacterial cell membrane.

LMD (but not LML) showed antilisterial activity at all temperatures including $5^{\circ} \mathrm{C}$, a standard milk refrigeration storage temperature. LMD, as a milk additive, may help with cross-contamination of $L$. monocytogenes in dairy products, a pathogen that can grow at refrigeration temperatures. Listerial load may be reduced or eliminated in food systems with less than $9 \%$ fat at $37^{\circ} \mathrm{C}$ and at $5{ }^{\circ} \mathrm{C}$ with less than $2 \%$ fat with the addition of LMD.

\section{Conclusion}

Carbohydrate fatty acid esters have well-documented microbial inhibitory and 
emulsification properties and thus have great potential for multiple uses in the food industry. Both LMD and LML showed antilisterial properties at different fat contents in milk at $37^{\circ} \mathrm{C}$, although LMD showed significant log reductions up to 9\% fat while LML showed significant $\log$ reductions to only 3.5\% fat. LMD also showed significant $\log$ reductions at $24^{\circ} \mathrm{C}$ and $5^{\circ} \mathrm{C}$ with up to $2 \%$ fat while LML was not effective at these temperatures. The decreased activity of LML at temperatures lower than $37^{\circ} \mathrm{C}$ may be due to a decreased solubility of this molecule as compared to LMD. The loss of antilisterial activity for each ester with an increase in fat content may be due to the ester partitioning into the fat phase in the milk samples. LMD, as a food additive, may play a role in increasing the safety of foods as it has shown significant microbial inhibitory activity towards Listeria in milk samples at multiple fat and temperature levels. Milk fat content and temperature are not the only parameters that can influence the antilisterial activity of carbohydrate esters, other environmental conditions such as $\mathrm{pH}$ may play significant roles. Additionally, the influence of lactose esters in dairy products with respect to taste, acceptance and overall functionality, is unknown. Further research can explore this and other parameters to determine the efficacy of the use of lactose esters in food systems for antilisterial activity.

\section{Acknowledgements}

This project was partially funded by the Utah Agricultural Experiment Station, Utah State University, and approved as paper number 9184.

\section{Conflicts of Interest}

The authors declare no conflicts of interest regarding the publication of this paper.

\section{References}

[1] Staron, J., Dabrowski, J.M., Cichon, E. and Guzik, M. (2017) Lactose Esters: Synthesis and Biotechnological Applications. Critical Reviews in Biotechnology, 38, 245-248. https://doi.org/10.1080/07388551.2017.1332571

[2] Neta, N.S., Teixeira, J.A. and Rodrigues, L.R. (2015) Sugar Ester Surfactants: Enzymatic Synthesis and Applications in Food Industry. Critical Reviews in Food Science and Nutrition, 55, 595-610. https://doi.org/10.1080/10408398.2012.667461

[3] Lee, S.-M., Sandhu, G. and Walsh, M.K. (2017) Growth Inhibitory Properties of Lactose Fatty Acid Esters. Saudi Journal of Biological Sciences, 24, 1483-1488. https://doi.org/10.1016/j.sjbs.2015.10.013

[4] Zhang, X., Wei, W., Cao, X. and Feng, F.Q. (2014) Characterization of Enzymatically Prepared Sugar Medium-Chain Fatty Acid Monoesters. Science of Food and Agriculture, 95, 1631-1637. https://doi.org/10.1002/jsfa.6863

[5] Fanun, M. (Ed.) (2017) Sugar Esters Microemulsions. Al-Quds University, East Jerusalem. https://doi.org/10.1016/B978-0-12-811653-1.09988-1

[6] Lee, S.-M., Wagh, A., Sandhu, G. and Walsh, M.K. (2018) Emulsification Properties of Lactose Fatty Acid Esters. Food and Nutrition Sciences, 9, 1341-1357. https://doi.org/10.4236/fns.2018.912096 
[7] Szuts, A. and Szabo-Revesz, P. (2012) Sucrose Esters as Natural Surfactants in Drug Delivery Systems-A Mini-Review. International Journal of Pharmaceutics, 433, 1-9. https://doi.org/10.1016/j.ijpharm.2012.04.076

[8] Nobmann, P., Smith, A., Dunne, J., Henehan, G. and Bourke, P. (2009) The Antimicrobial Efficacy and Structure Activity Relationship of Novel Carbohydrate Fatty Acid Derivatives against Listeria Spp. and Food Spoilage Microorganisms. International Journal of Food Microbiology, 128, 440-445. https://doi.org/10.1016/j.ijfoodmicro.2008.10.008

[9] Wagh, A., Shen, S., Shen, F.A., Miller, C.D. and Walsh, M.K. (2012) Effect of Lactose Monolaurate on Pathogenic and Nonpathogenic Bacteria. Applied and Environmental Microbiology, 78, 3465-8. https://doi.org/10.1128/AEM.07701-11

[10] Zhao, L., Zhang, H., Hao, T. and Li, S. (2015) In vitro Antibacterial Activities and Mechanism of Sugar Fatty Acid Esters Against Five Food-Related Bacteria. Food Chemistry, 187, 370-377. https://doi.org/10.1016/j.foodchem.2015.04.108

[11] Shao, S.-Y., Shi, Y.-G., Wu, Y., Bian, L.-Q., Zhu, Y.-J., Huang, X.-Y., Pan, Y., Zeng, L.-Y. and Zhang, R.-R. (2018) Lipase-Catalyzed Synthesis of Sucrose Monolaurate and Its Antibacterial Property and Mode of Action against Four Pathogenic Bacteria. Molecules, 23, 1118. https://doi.org/10.3390/molecules23051118

[12] Walsh, M.K., Bombyk, R.A., Wagh, A, Bingham, A. and Berreau, L.M. (2009) Synthesis of Lactose Monolaurate as Influenced by Various Lipases and Solvents. Journal of Molecular Catalyst B: Enzymatic, 60, 171-177. https://doi.org/10.1016/j.molcatb.2009.05.003

[13] Chen, Y., Nummer, B. and Walsh, M.K. (2013) Antilisterial Activity of Lactose Monolaurate in Milk, Drinkable Yogurt and Cottage Cheese. Letters in Applied Microbiology, 58, 156-162. https://doi.org/10.1111/lam.12169

[14] Xiao, D., Ye, R., Davidson, P.M., Hayes, D.G., Golden, D.A. and Zhong, Q. (2011) Sucrose Monolaurate Improves the Efficacy of Sodium Hypochlorite against Escherichia coli O157:H7 on Spinach. International Journal of Food Microbiology, 145, 64-68. https://doi.org/10.1016/j.ijfoodmicro.2010.11.029

[15] Yang, C.-M., Luedecke, L.O., Swanson, B.G. and Davidson, P.M. (2003) Inhibition of Microorganisms in Salad Dressing by Sucrose and Methylglucose Fatty Acid Monoesters. Journal of Food Process Preservation, 27, 285-298. https://doi.org/10.1111/j.1745-4549.2003.tb00518.x

[16] U.S. Food and Drug Administration, Code of Federal Regulations Title 21, Part 172, Food Additives Permitted for Direct Addition to Food for Human Consumption, Section 172.859, Sucrose Fatty Acid Esters. https://www.accessdata.fda.gov/scripts/cdrh/cfdocs/cfcfr/cfrsearch.cfm?fr=172.859

[17] Walsh, M.K., McMahon, D.J. and Duncan, S. (2013) Milk and Dairy Foods. In: Hui, Y.H., Ed., Food Chemistry: Principles and Applications, 3rd Edition, Science Technology System, West Sacramento. 